\title{
Relationship between fall risks and activities of daily living in older individuals
}

Abstract: Objective: To investigate the relationship between fall risks and maintaining activities of daily living in individuals aged 65 and over. Methods: This study is cross-sectional. It was conducted with 233 individuals who were aged 65 and over in Family Health Centers located in the eastern part of Turkey between February and June 2018.

Results: The mean older individuals' DENN Fall Risks Assessment Scale score was $11.73 \pm 7.13$, and $62.2 \%$ of the participants were in the high-risk group. Barthel Index of Activities of Daily Living (ADL) mean score was $68.03 \pm 25.36$, and $45.1 \%$ of the participants were in the moderately dependent group. There was a statistically significant, negative correlationship between Barthel Index of ADL score and age and DENN Fall Risks Assessment Scale score. In addition, there was a statistically significant, positive relationship between the DENN Fall Risks Assessment Scale score and age $(p<0.01)$.

Conclusions: This study found that level of dependency and fall risks increased with the increase in age. Effective global and multidisciplinary interventions are needed to decrease older individuals' dependency levels and fall risks today when the number of older individuals is increasing.

Keywords: activities of daily living • dependency • older • fall risk

(c) Shanxi Medical Periodical Press.

\section{Introduction}

The global increase in the older population has also increased the pressure on the health systems and services required for the care and treatment of older individuals. Demographic trends in the following 30 years show that the adult population aged 65 and over will become nearly 2 billion by the year 2050. ${ }^{1,2}$ The proportion of older individuals has been increasing rapidly in Turkey like in the world. While $8.7 \%$ of the world population is composed of an older population, this proportion was $8.3 \%$ in Turkey in $2016 .{ }^{3}$ Number and proportion of older individuals in the total population make old age an important social problem in modern society. Increase in individuals' life expectancy brings along problems such as health problems that prevent older individuals from taking care of themselves, becoming dependent on others, and requiring care..$^{4,5}$

How to cite this article: Arli SK, Yildiz M, Bakan AB. Relationship between fall risks and activities of daily living in older individuals. Front Nurs. 2020;3:249-256. 
With the aging process, older individuals experience biological, psychological, and physiological declines and difficulties in activities of daily living (ADL) as well as visible insufficiency in their functions. These changes experienced by older individuals limit the ADL and negatively affect their quality of life.$^{6,7}$ In the 1970 s, Nancy Roper, Winifred W. Logan and Alison J. Tierney developed a Nursing Model, based on ADL, that provides a systematic presentation of $A D L$ and a rational method of approaching human beings with all dimensions to identify the importance of ADL. ADL presents individuals' activities that they carry out to maintain daily life. The main notion of this model is to identify the extent to which people can maintain their daily life independently on their own. ${ }^{8}$

Older individuals' self-sufficiency decreases gradually as their health problems increase, and there are increases in accidents and fall rates. Although falls are not specific to old age, it is an important health problem whose prevalence increases with age and which causes mortality and morbidity in older individuals..$^{9,10}$ Globally, approximately one-third of individuals aged 65 and over fall annually, and $20-30 \%$ of these falls result in physical injury. In addition, severe injuries in older individuals increase care costs. ${ }^{11,12}$ Falls are the primary causes of fatal and nonfatal injuries in individuals over 65 years old. In America, approximately 27,000 older individuals died due to falls in $2014 ; 2.8$ million patients were treated in emergency services due to injuries caused by falls, and approximately 800,000 of these patients were hospitalized..$^{13}$

With the aging process, older persons experience regression, with visible insufficiency, and difficulty in daily living activities. These changes in elderly persons restrict the daily living activities of individuals, with negative impacts on their quality of life. In particular, falls represent a phenomenon that causes fear and concern in older persons. Although falls are not limited to older persons, it is an important health issue the prevalence of which increases with age, causing mortality and morbidity in older persons. However, the literature states that fall risk increased in older persons, particularly those under treatment at hospitals, and increased subject to deterioration of medical conditions, polypharmacy, environmental factors, and confusion. Also, the fear of falling affects the feeling of confidence in older persons in relation to their daily activities, reducing their ability to perform daily living activities and leading to a less active lifestyle. ${ }^{14,15}$

Study results showed that physical performance is very important for the realization of stability and flexibility in the older. It suggests taking part in older rehabilitation of the applications for the protection and improvement of body flexibility and balance. ${ }^{16}$ Another study result recommended that "Safe-Movement and Walking Program" is generalized and more applied in nursing homes for decreasing fear of falling in the older individuals living in a nursing home. ${ }^{17}$

\section{Materials and methods}

\subsection{Study design}

This cross-sectional study was conducted in Family Health Centers located in Ağrı city center between February and June 2018.

The target population of the study were individuals who were aged 65 and over who lived in Ağrı. No sampling was performed, the study involved 233 individuals who applied to Family Health Centers; who did not have Alzheimer's, dementia, paralysis, or terminal cancer; who had sufficient communication skills; and who volunteered to participate in the study.

\subsection{Data collection}

Data were collected using the Socio-demographic Form, DENN Fall Risks Assessment Scale, and Barthel Index of ADL (BI). Data were collected by the researchers via face to face interviews conducted with older individuals. Data collection took approximately 15 to 20 minutes.

\subsubsection{Socio-demographic form}

The form, which was prepared by the researcher in line with the related literature, was composed of seven questions that aimed to collect information about age, gender, marital status, and income level. ${ }^{18,19}$

\subsubsection{DENN Fall Risks Assessment Scale}

The scale is composed of nine main sub-scales developed by Nebraska's Medicare Quality Improvement Organization by benefiting from the Falls Management Guidelines. ${ }^{20}$ The form was adapted to Turkish by Tekin et al. ${ }^{21}$ The total score Kappa value of the scale was found 0.753 . Assessment is made according to the total score, and the individual's fall risk is identified accordingly. Scores are categorized as "low risk" for the scores between 0 and 5 , "moderate risk" for the scores between 6 and 9, and "high risk" for the scores 10 and above. ${ }^{21}$ Cronbach's Alpha value was found 0.79 in the present study.

\subsubsection{Barthel Index of ADL}

Barthel Index, developed by Mahoney and Barthel in 1965, investigates patients' independency 
level in ADL. ${ }^{22}$ Validity and reliability of the scale for Turkey was performed by Küçükdeveci et al. ${ }^{23}$ with neurology patients; Cronbach's Alpha value was found 0.93. ${ }^{23}$ Barthel Index is used for the identification of individuals' independency levels in their activities. Barthel Index scores range between 0 and 100; while 0 indicates total dependency, 100 indicates independency. According to Barthel Index, scores between 0 and 20 indicate dependent individuals; scores from 21 to 61 indicate highly dependent individuals, scores from 62 to 90 indicate moderately dependent individuals, and 100 indicates independent individuals. ${ }^{22,23}$ Cronbach's Alpha value was found.88 in the present study.

\subsection{Analysis of the data}

Data were analyzed using SPSS statistical package. The analysis was performed using descriptive statistics, Kolmogorov-Smirnov, Mann-Whitney U, Kruskal-Wallis, and Spearman correlation tests.

\subsection{Ethical considerations}

Approval was obtained from Ağrı İbrahim Çeçen University Scientific Research Ethics Committee and written permission was obtained from the institution where the study was conducted (City Health Administrative). The participants were provided with the necessary explanations, and verbal consent was obtained from those who accepted to participate in the study.

\section{Results}

Of all the participants, $57.1 \%$ were female, $71.2 \%$ were married, $50.6 \%$ graduated from secondary school, $40.3 \%$ did not have a wage-earning job, $63.9 \%$ had income equal to expenses, $35.6 \%$ lived with their spouse and children, $77.7 \%$ did not need support about anything, $63.1 \%$ had a chronic disease, $58.4 \%$ used medicine regularly, and the average age of the group was $70.18 \pm 7.09$ (Table1).

Findings showed that older individuals' DENN Fall Risks Assessment Scale mean score was $11.73 \pm 7.13$; scores ranged between 0 and 27 . Categorical analysis of the scale score showed that $62.2 \%$ of the participants were in the high-risk group. Barthel Index of ADL mean score was $68.03 \pm 25.36$ with scores ranging from 0 to 100. Categorical analysis of the scale score showed that $45.1 \%$ of the participants were in the moderately dependent group (Table 2).

DENN Fall Risks Assessment Scale mean score was found to be significantly higher in those who were single/widowed, who graduated from secondary school,

\begin{tabular}{|c|c|c|}
\hline Variables & $N$ & $\%$ \\
\hline \multicolumn{3}{|l|}{ Gender } \\
\hline Female & 133 & 57.1 \\
\hline Male & 100 & 42.9 \\
\hline \multicolumn{3}{|l|}{ Marital status } \\
\hline Married & 166 & 71.2 \\
\hline Single/Widowed & 67 & 28.8 \\
\hline \multicolumn{3}{|l|}{ Education level } \\
\hline Illiterate & 87 & 37.3 \\
\hline Secondary School & 118 & 50.6 \\
\hline High School/University & 28 & 12.0 \\
\hline \multicolumn{3}{|l|}{ Working status } \\
\hline Has no wage-earning job & 94 & 40.3 \\
\hline Public Servant/Private Sector Worker & 43 & 18.5 \\
\hline Retired & 41 & 17.6 \\
\hline Self-employed & 55 & 23.6 \\
\hline \multicolumn{3}{|l|}{ Income level } \\
\hline Income less than expenses & 50 & 21.5 \\
\hline Income equal to expenses & 149 & 63.9 \\
\hline Income more than expenses & 34 & 14.6 \\
\hline \multicolumn{3}{|l|}{ People they live with } \\
\hline Living alone & 16 & 6.9 \\
\hline Living with spouse & 45 & 19.3 \\
\hline Living with children & 63 & 27.0 \\
\hline Living with spouse and children & 83 & 35.6 \\
\hline Other & 26 & 11.2 \\
\hline \multicolumn{3}{|l|}{ Need for support } \\
\hline Yes & 52 & 22.3 \\
\hline No & 181 & 77.7 \\
\hline \multicolumn{3}{|l|}{ Having a chronic disease } \\
\hline Yes & 147 & 63.1 \\
\hline No & 86 & 36.9 \\
\hline \multicolumn{3}{|l|}{ Regular use of medicine } \\
\hline Yes & 136 & 58.4 \\
\hline No & 97 & 41.6 \\
\hline
\end{tabular}

Table 1. Socio-demographic features of the participants $(n=233)$.

\begin{tabular}{lcc}
\hline Categorical Assessment of the Scales & $n$ & $\%$ \\
\hline \hline DENN Fall Risks Assessment Scale & 53 & 22.7 \\
Low Risk (0 to 5 point) & 35 & 15.0 \\
Moderate Risk (6 to 9 points) & 145 & 62.2 \\
High Risk (10 points and over) & & \\
Barthel Index of Activities of Daily Living (BIADL) & 12 & 5.2 \\
Totally Dependent (0 to 20 points) & 71 & 30.5 \\
Highly Dependent (21 to 61 points) & 105 & 45.1 \\
Moderately Dependent (62 to 90 points) & 14 & 6.0 \\
Mildly dependent (91 to 99 points) & 31 & 13.3 \\
Totally Independent (100 points) &
\end{tabular}

Table 2. The participants' DENN Fall Risks Assessment Scale and Barthel Index of Activities of Daily Living Scores. 
who worked in public/private sector, and who had a chronic disease $(p<0.05)$. There were no differences between the groups in terms of gender, income level, people they live with, regular use of medicine, and needing support (Table 3).

Barthel Index of ADL mean score was found to be significantly lower in those who were single/widowed, who worked in one-day jobs, who lived with their relatives, who had a chronic disease, who used medicine regularly, and who needed support $(p<0.05)$. No differences were found between the groups in terms of gender, education level, and income level (Table 4).

There was a negative, statistically significant correlationship between Barthel Index of ADL score and age and DENN Fall Risks Assessment Scale score; there was a positive, statistically significant correlationship between DENN Fall Risks Assessment Scale and age $(p<0.01)$ (Table 5).

\begin{tabular}{|c|c|c|c|c|c|}
\hline Variables & $n$ & $\mathrm{M} \pm \mathrm{SD}$ & $U$ & $\mathrm{KW}$ & $P$ \\
\hline Gender & & & 6604.5 & & 0.929 \\
\hline Female & 133 & $11.65 \pm 7.10$ & & & \\
\hline Male & 100 & $11.78 \pm 7.17$ & & & \\
\hline Marital Status & & & 4516.0 & & $0.025^{\star}$ \\
\hline Married & 166 & $11.03 \pm 6.82$ & & & \\
\hline Single/Widowed & 67 & $13.45 \pm 7.61$ & & & \\
\hline Education Level & & & & 13.615 & $0.001^{\star \star}$ \\
\hline Illiterate & 87 & $12.18 \pm 7.11$ & & & \\
\hline Secondary School & 118 & $12.55 \pm 6.90$ & & & \\
\hline High School/University & 28 & $6.82 \pm 6.38$ & & & \\
\hline Working status & & & & 26.691 & $0.000^{* *}$ \\
\hline Has no wage-earning job & 94 & $11.32 \pm 7.07$ & & & \\
\hline Public Servant/Private Sector Worker & 43 & $14.47 \pm 7.12$ & & & \\
\hline Retired & 41 & $7.32 \pm 6.43$ & & & \\
\hline One-day jobs & 55 & $13.56 \pm 6.14$ & & & \\
\hline Income Level & & & & 5.509 & 0.064 \\
\hline Income less than expenses & 50 & $11.76 \pm 7.24$ & & & \\
\hline Income equal to expenses & 149 & $11.10 \pm 7.07$ & & & \\
\hline Income more than expenses & 34 & $14.41 \pm 6.78$ & & & \\
\hline People they live with & & & & 9.021 & 0.061 \\
\hline Living alone & 16 & $9.50 \pm 5.62$ & & & \\
\hline Living with spouse & 45 & $11.11 \pm 7.41$ & & & \\
\hline Living with children & 63 & $13.60 \pm 6.98$ & & & \\
\hline Living with spouse and children & 83 & $10.75 \pm 6.82$ & & & \\
\hline Other (relatives) & 26 & $12.73 \pm 8.10$ & & & \\
\hline Having a chronic disease & & & 4999.0 & & $0.008^{\star *}$ \\
\hline Yes & 147 & $12.76 \pm 6.62$ & & & \\
\hline No & 86 & $9.95 \pm 7.65$ & & & \\
\hline Regular use of Medicine & & & 5781.5 & & 0.108 \\
\hline Yes & 136 & $12.43 \pm 7.05$ & & & \\
\hline No & 97 & $10.74 \pm 7.16$ & & & \\
\hline Need for support & & & 4324.0 & & 0.372 \\
\hline Yes & 52 & $12.69 \pm 6.08$ & & & \\
\hline No & 181 & $11.45 \pm 7.39$ & & & \\
\hline
\end{tabular}

Note: ${ }^{\star} P<0.05 ;{ }^{\star \star} P<0.01$.

Table 3. The Participants' DENN fall Risks Assessment Scale scores distributions according to socio-demographic characteristics $(n=233)$. 


\begin{tabular}{|c|c|c|c|c|c|}
\hline Variables & $N$ & $M \pm S D$ & $U$ & $\mathrm{KW}$ & $P$ \\
\hline Gender & & & 6532.0 & & 0.816 \\
\hline Female & 133 & $67.29 \pm 26.58$ & & & \\
\hline Male & 100 & $69.00 \pm 23.73$ & & & \\
\hline Marital status & & & 4547.0 & & $0.029^{*}$ \\
\hline Married & 166 & $70.75 \pm 23.60$ & & & \\
\hline Single/Widowed & 67 & $61.27 \pm 28.34$ & & & \\
\hline Education level & & & & 1.535 & 0.464 \\
\hline Illiterate & 87 & $65.17 \pm 30.08$ & & & \\
\hline Secondary School & 118 & $69.11 \pm 20.56$ & & & \\
\hline High School/University & 28 & $72.32 \pm 27.57$ & & & \\
\hline Working status & & & & 21.240 & $0.000^{* *}$ \\
\hline Has no wage-earning job & 94 & $66.17 \pm 29.21$ & & & \\
\hline Public Servant/Private Sector Worker & 43 & $69.77 \pm 16.51$ & & & \\
\hline Retired & 41 & $81.10 \pm 20.29$ & & & \\
\hline One-day jobs & 55 & $60.09 \pm 23.95$ & & & \\
\hline Income level & & & & 5.669 & 0.059 \\
\hline Income less than expenses & 50 & $60.80 \pm 29.58$ & & & \\
\hline Income equal to expenses & 149 & $71.24 \pm 23.32$ & & & \\
\hline Income more than expenses & 34 & $64.56 \pm 25.39$ & & & \\
\hline People they live with & & & & 12.212 & $0.016^{*}$ \\
\hline Living alone & 16 & $63.75 \pm 30.69$ & & & \\
\hline Living with spouse & 45 & $69.89 \pm 25.03$ & & & \\
\hline Living with children & 63 & $68.25 \pm 22.79$ & & & \\
\hline Living with spouse and children & 83 & $73.49 \pm 21.42$ & & & \\
\hline Other (relatives) & 26 & $49.42 \pm 32.07$ & & & \\
\hline Having a chronic disease & & & 4566.0 & & $0.000^{* *}$ \\
\hline Yes & 147 & $63.64 \pm 26.18$ & & & \\
\hline No & 86 & $75.52 \pm 22.08$ & & & \\
\hline Regular use of Medicine & & & 5485.0 & & $0.028^{*}$ \\
\hline Yes & 136 & $64.12 \pm 28.49$ & & & \\
\hline No & 97 & $73.51 \pm 18.99$ & & & \\
\hline Need for support & & & 3792.0 & & $0.032^{*}$ \\
\hline Yes & 52 & $60.00 \pm 30.41$ & & & \\
\hline No & 181 & $70.33 \pm 23.30$ & & & \\
\hline
\end{tabular}

Note: ${ }^{\star} P<0.05 ;{ }^{\star} * P<0.01$.

Table 4. The Participants' Barthel Index of activities of daily living scores distribution according to socio-demographic features $(n=233)$.

\section{Discussion}

The World Health Organization considers falling as one of the most important health problems of old age. Falling is a situation that negatively affects the quality of life, leads to loss of independency in ADL, and causes fear and anxiety in older people. ${ }^{24,25}$ According to a report published in 2004, one-third of older individuals fall every year, and this proportion was higher in individuals aged
75 and over. Injuries in $20-30 \%$ of the older individuals who fell decreased their mobility and independency and increased risk of premature death. ${ }^{26} \mathrm{~A}$ review of the literature indicates that women and people in advanced age groups have high fall risks due to decreased muscular force. ${ }^{14}$ This study found no significant differences between gender and fall risks, but it might change from society to society. In addition, prevalence and risk of falls are high in people aged 65 and over. ${ }^{27}$ 


\begin{tabular}{|c|c|c|c|c|c|c|}
\hline \multirow[t]{2}{*}{ Items } & \multicolumn{2}{|c|}{$\begin{array}{l}\text { DENN Fall Risks Assessment } \\
\text { Scale Total Score }\end{array}$} & \multicolumn{2}{|c|}{$\begin{array}{l}\text { Barthel Index of Activities of } \\
\text { Daily Living Total Score }\end{array}$} & \multicolumn{2}{|c|}{ Age } \\
\hline & $r$ & $p$ & $r$ & $p$ & $r$ & $p$ \\
\hline DENN Fall Risks Assessment Scale Total Score & & 1 & & & & \\
\hline Barthel Index of Activities of Daily Living Total Score & -0.521 & 0 & 1 & & & \\
\hline Age & 0.261 & 0 & -0.299 & 0 & & 1 \\
\hline
\end{tabular}

Note: $P<0.01$.

Table 5. Relationship between DENN Fall Risks Assessment Scale and Barthel Index of Activities of Daily Living Scores.

Falls cause loss of mobility and independency in $20-30 \%$ of older individuals and severe injuries in $10 \%$, prolong care duration, increase the need for medical care and treatment as well as health care cost by affecting health care expenses. ${ }^{28}$ Old age is also associated with walking and balance changes increased inactivity, more severe chronic cases, and more prescribed medicine use; all of these are risk factors for falls. ${ }^{14}$ In line with the related literature, fall risk was found to be higher in individuals with a chronic disease.

Studies in our country showed that dependency levels were higher in individuals aged 65 and over, and dependency increased with the increase in age. ${ }^{29}$ This study found that older individuals' dependency was at a moderate level and that dependency demonstrated an increase with age. Other studies in our country also found older individuals to be moderately dependent. ${ }^{30,31}$ This study found that dependency levels were higher in older individuals who had a chronic disease and who used medicine regularly. Other studies also reported that dependency levels increased with the increase in the number of older individuals' chronic diseases and use of medicine. ${ }^{29-31}$

This study also showed that according to Barthel Index classification, fall risks increase as the dependency level increases. Beyazay et al. ${ }^{30}$ also found that patients' fall risks increased with the increase in their dependency. There is a global necessity for increasing awareness about the importance of physical activity among older individuals. "Healthy ageing" traditionally focuses on the prevention of chronic diseases. However, decreasing falls and dependency requires more efforts to protect independent physical and cognitive functions, mental health, and well-being. ${ }^{1,32}$

Related literature indicates that it is possible to prevent older people's falls, and health care providers (doctors, nurses, doctor assistants, physiotherapists, etc.) could play an important role in this issue by initiating appropriate plans and interventions. ${ }^{33}$ Health care providers should discuss the issue of preventing falls with their patients and take necessary precautions. Regular physical activity is reported to decrease mortality and chronic disease risks and enhance well-being and independency in older individuals. One of the most important approaches that could be used in retarding age-related morbidity is reported to be increasing physical activity. ${ }^{1,34}$

The limitation of this study is that it was conducted in one region and with a small group of participants.

\section{Conclusions}

In conclusion, the dependency level and fall risks increase with the increase in age. In this regard, assessments should be performed with standardized scales and forms, and necessary precautions should be taken accordingly. In addition, innovative efforts are required to study physical inactivity, prevent loss of muscle force, and maintain balance in the older population. Special investments and policies should be provided for maintaining healthy aging. In addition, nurses can play an important role to decrease older individuals' dependency levels and fall risks definition. Nursing policies in line with these should be applied at regional and national levels to decrease illnesses and burden of incapacity among older individuals.

\section{Disclosure Statement}

No potential conflicts of interest were disclosed.

\section{Acknowledgments}

The authors would like to thank the focus group participants for their time. Specific contributions to the study and/or manuscript of each author are listed below:

SKA and ABB: Study conception/design.

$A B B$ and $M Y$ : Data collection/analysis.

SKA: $\quad$ Drafting of manuscript.

SKA and ABB: Critical revision for intellectual content.

SKA: Study supervision. 


\section{Ethical approval}

All procedures performed in studies involving human participants were in accordance with the ethical standards of the institutional and/or national research committee and with the 1964 Helsinki Declaration and its later amendments or comparable ethical standards.

\section{Conflict of interest}

The authors declare that they have no competing interests.

\section{References}

1. Bauman A, Merom D, Bull FC, Buchner DM, Singh MAF. Updating the evidence for physical activity: summative reviews of the epidemiological evidence, prevalence, and interventions to promote "active aging". Gerontologist. 2016;56:S268-S280.

2. Briggs AM, Cross MJ, Hoy DG, et al. Musculoskeletal health conditions represent a global threat to healthy aging: a report for the 2015 World Health Organization world report on ageing and health. Gerontologist. 2016;56:S243-S255.

3. Bektaş, H, Kalav, S. Comprehensive geriatric assessment. Int. Refereed J Nurs Res. 2017;11:201-231.

4. Bakan AB, Arli SK, Varol E. Identification of nursing students' attitudes toward older people. Contemp Nurse. 2018;54:284-292.

5. Kalınkara V, Kalaycı I. Life satisfaction, care burden and burnout of the individuals who have a caregiver service to the elderly at home. Elderly Issues Res J. 2017;10:19-39.

6. Son H, Son YJ, Kim H, Lee Y. Effect of psychosocial interventions on the quality of life of patients with colorectal cancer: a systematic review and metaanalysis. Health Qual Life Outcomes. 2018;16:119.

7. Tourani S, Behzadifar M, Martini M, et al. Healthrelated quality of life among healthy elderly Iranians: a systematic review and meta-analysis of the literature. Health Qual Life Outcomes. 2018;16:18.

8. Jenkins J, Solomon J, Whittam S. Applying the Roper. Logan. Tierney model in Practice. 2nd ed. Elsevier Limited; 2012.

9. Hou WH, Kang CM, Ho MH, Kuo JMC, Chen HL, Chang WY. Evaluation of an inpatient fall risk screening tool to identify the most critical fall risk factors in inpatients. J Clin Nurs. 2017;26:698-706.

10. Poudel A, Peel NM, Nissen LM, Mitchell CA, Gray LC, Hubbard RE. Adverse outcomes in relation to polypharmacy in robust and frail older hospital patients. J Am Med Dir Assoc. 2016;17:767.e9-767.e13.

11. Carande-Kulis V, Stevens JA, Florence CS, Beattie $\mathrm{BL}$, Arias I. A cost-benefit analysis of three older adult fall prevention interventions. J Safety Res. 2015;52:65-70.
12. Khanuja K, Joki J, Bachmann G, Cuccurullo S. Gait and balance in the aging population: fall prevention using innovation and technology. Maturitas. 2018;110:51-56.

13. Bergen G, Stevens M, Burnes E. Falls and fall injuries among adults aged $\geq 65$ years-United States, 2014. MMWR Morb Mortal Wkly Rep. 2016;65:993-998.

14. Çınarlı T, Koç Z. Effect of risk and fear of falling on quality of life and daily living activities in elderly over 65. Gümüşhane Univ J Health Sci. 2015;4:660-679.

15. Şahin H, Erkal S. Evaluation of the elderly' falls efficacy by their status of having a home accident and daily life activities. J Hum Sci. 2017;14: 2308-2316.

16. Sertel M, Yümin ET. The effects of flexibility and short physical performance on balance in the elderly. J Hum Soc Sci Res. 2017;6:591-601.

17. Şen G, Erol S. The effects of safe-movement and walking program on reducing the fear of falling in elderly individuals living in a nursing home. HSP. 2018;5:387-396.

18. Ambrose AF, Paul G, Hausdorff JM. Risk factors for falls among older adults: a review of the literature. Maturitas. 2013;75:51-61.

19. Gouveia BR, Jardim HG, Martins MM, et al. An evaluation of a nurse-led rehabilitation programme (the ProBalance Programme) to improve balance and reduce fall risk of community-dwelling older people: a randomised controlled trial. Int $J$ Nurs Stud. 2016;56:1-8.

20. Gray J. Protecting hospice patients: a new look at falls prevention. AJHPM. 2007;24:242-247.

21. Tekin DE, Kara N, Utlu Tan N, Arkuran F. The Turkish adaptation of the fall risk assessment scale developed by the Delmarva foundation: a reliability and validity study. HEAD. 2013;10:45-50.

22. Mahoney FI, Barthel D. Functional evaluation: The Barthel Index. Md Med J. 1965;14:56-61.

23. Küçükdeveci $A A$, Yavuzer $G$, Tennant $A$, Süldür $\mathrm{N}$, Sonel B, Arasil T. Adaptation of the modified 
Barthel Index for use in physical medicine and rehabilitation in Turkey. Scand J Rehabil Med. 2000; 32:87-92.

24. Liu TW, Ng GY, Chung RC, Ng SMS. Cognitive behavioural therapy for fear of falling and balance among older people: a systematic review and metaanalysis. Age Ageing. 2018;47:520-527.

25. Pandya C, Magnuson A, Dale W, Lowenstein L, Fung C, Mohile SG. Association of falls with healthrelated quality of life (HRQOL) in older cancer survivors: a population based study. J Geriatr Oncol. 2016;7:201-210.

26. Stevens JA, Rudd RA. Circumstances and contributing causes of fall deaths among persons aged 65 and older: United States, 2010. J Am Geriatr Soc. 2014;62:470-475.

27. Johnell K, Jonasdottir Bergman G, Fastbom J, Danielsson B, Borg N, Salmi P. Psychotropic drugs and the risk of fall injuries, hospitalisations and mortality among older adults. Int J Geriatr Psychiatry. 2017;32:414-420.

28. Manning KJ, Wolfson LI. Decreasing fall risk: intensive cognitive training and blood pressure control. J Am Geriatr Soc. 2017;65:906-908.
29. Şahin S, Boyacıoğlu H, Taşar-Tosun P, et al. The functional dependency rates of Bornova district residents over age 65. Ege J Med. 2016;55:65-70.

30. Beyazay S, Durna Z, Akin S. Assessment of risk of falls in the elderly and associated factors with falls. Turkiye Klinikleri J Nurs Sci. 2014;6:1-12.

31. Kankaya $H$, Karadakovan $A$. The effects of daily life activity levels on the quality of life and life satisfaction of elderly. Gümüşhane Univ J Health Sci. 2017;6:21-29.

32. Gouveia BR, Jardim HG, Martins MM, et al. An evaluation of a nurse-led rehabilitation programme (the ProBalance Programme) to improve balance and reduce fall risk of community-dwelling older people: a randomised controlled trial. Int $J$ Nurs Stud. 2016;56;1-8.

33. Gillespie LD, Robertson MC, Gillespie WJ, et al. Interventions for preventing falls in older people living in the community. Cochrane Database Syst Rev. 2012;9:CD007146.

34. Fielding R, Guralnik J, King A, et al. Dose of physical activity, physical functioning and disability risk in mobility-limited older adults: results from the LIFE study randomized trial. PLoS One. 2017;12:e0182155. 